\title{
Effects of Cost and Benefit of Prosocial Behavior on Reputation
}

$\operatorname{AUTHOR}(\mathrm{S}):$

Kawamura, Yuta; Ohtsubo, Yohsuke; Kusumi, Takashi

\section{CITATION:}

Kawamura, Yuta ...[et al]. Effects of Cost and Benefit of Prosocial Behavior on Reputation. Social Psychological and Personality Science 2021, 12(4): 452-460

ISSUE DATE:

2021-05-01

URL:

http://hdl.handle.net/2433/263148

\section{RIGHT:}

This is the accepted manuscript of the following article: 'Social Psychological and Personality Science' 2021, 12(4) 452 460. Copyright @ The Author(s) 2020. DOI: 10.1177/1948550620929163; This is not the published version. Please cite only the published version.この論文は出版社版でありません。引用の際には出版社版をご確認ざ利用ください。 
Running Head: COST AND BENEFIT OF PROSOCIAL BEHAVIOR

1

2

3

4

5

6

7

8

9

10

11

12

13

$14{ }^{1}$ Department of Psychology, Kobe University, Japan.

$15{ }^{2}$ Japan Society for the Promotion of Science, Tokyo, Japan

$16{ }^{3}$ Graduate School of Education, Kyoto University, Japan.

18 Correspondence should be addressed to:

19 Yuta Kawamura

20 Department of Psychology, Kobe University

21 1-1 Rokkodai-cho, Nada-ku, Kobe 657-8501, Japan

22 E-mail address: kawamura@lit.kobe-u.ac.jp

\section{Effects of Cost and Benefit of Prosocial Behavior on Reputation}

(author version) 
COST AND BENEFIT OF PROSOCIAL BEHAVIOR

\section{Abstract}

2 Prosocial behavior consists of a cost to the actor and a benefit of others. Previous studies have

3 shown that prosocial actors generally receive positive social evaluations from observers.

4 However, it is unknown how each component of prosocial behavior (i.e., cost and benefit)

5 influences the two dimensions of person perception (i.e., warmth and competence). Thus, three

6 studies investigated the independent effects of cost and benefit on the perceived warmth and

7 competence of the actor. In Study 1, participants read a series of vignettes about a protagonist

8 incurring a cost to benefit another individual and rated the warmth and competence of each

9 protagonist. Although benefit enhanced both perceived warmth and competence, cost enhanced

10 only perceived warmth. Studies $2 \mathrm{a}$ and $2 \mathrm{~b}$ separately manipulated costs and benefits of prosocial

11 behaviors in vignettes, and confirmed the results of Study 1 . Thus, this study demonstrated the

12 independent effects of cost and benefit on person perception.

Keywords: altruism, helping/prosocial behavior, reputation, person perception, warmth, 


\section{COST AND BENEFIT OF PROSOCIAL BEHAVIOR}

\section{Effects of Cost and Benefit of Prosocial Behavior on Reputation}

On a daily basis, people exhibit various forms of prosocial behavior. Although the definition of prosocial behavior is debatable, prosocial behaviors typically entail benefits toward someone else and a cost to the individual performing the behavior (e.g., Fehr \& Fischbacher, 2003; Kurzban, Burton-Chellew, \& West, 2015; West, Griffin, \& Gardner, 2007). Such prosocial behaviors are generally praised by others. However, the cost-benefit ratio varies substantially across instances of prosocial behaviors. For example, suppose that someone donates used household items to a disaster zone. Disaster victims may find them extremely valuable even when the cost is negligible to the donor. Now suppose that the donor spent substantial money on canned foods. Despite the donor's cost, the donated canned foods would be almost worthless if there are no can openers available in the disaster zone. In these two instances, how do people evaluate the donors? In the present study, we independently manipulated the level of costs to the prosocial actors and benefits to the recipients and examined the effects of these two variables on impressions of prosocial actors.

People generally praise prosocial behaviors and even confer a high status upon the prosocial actors (Hardy \& Van Vugt, 2006; Willer, 2009). Similarly, people tend to trust (Barclay, 2004) and empathize with (Zheng et al., 2016) prosocial actors. Moreover, charitable organizations praise major donors by providing them with symbolic awards, such as medals (see Lacetera \& Macis, 2010). As such, it is well-established that prosocial behaviors are favorably evaluated. However, previous studies have not separately examined the effects of two components of prosocial behaviors: the costs to the actors and benefits to the recipients. Although one might assume that the relationship between the cost of prosocial behaviors and benefits to the recipients is linear (i.e., the more costly to the actor, the more beneficial for the 


\section{COST AND BENEFIT OF PROSOCIAL BEHAVIOR}

1 recipient), this does not necessarily hold true in the real world. For example, expensive gifts sometimes fail to please recipients (e.g., Dorsch \& Kelley, 1994; Flynn \& Adams, 2009), and generously motivated behaviors sometimes displease recipients (e.g., Bolger \& Amarel, 2007; Feeney, 2004). Moreover, in real-life social exchanges, costs and benefits can take various forms: costs can comprise effort, time, and money (e.g., Duval, Duval, \& Neely, 1979) and benefits can be physical, financial, or psychological. Therefore, it is possible that costs and benefits differ in terms of their resource type. For example, one's time cost (e.g., listening to a partner's problems for a long period of time) may produce a psychological benefit in the partner (e.g., relief of

9 stresses). In such cases, it is not reasonable to expect a linear relationship between cost and benefit because they are not convertible from one form to the other.

Previous studies have examined many factors that influence the evaluation of prosocial actors, which include incentives for prosocial behaviors (Barasch, Levine, Berman, \& Small, 2014; Lin-Healy \& Small, 2012), the type of relationship between the actor and beneficiary

14 (Kawamura \& Kusumi, 2017; Lin-Healy \& Small, 2013), and motives of prosocial behaviors

15 (Carlson \& Zaki, 2018; Newman \& Cain, 2014). However, only a few studies have separated the 16 effects of the costs and benefits of prosocial behaviors (Flynn \& Adams, 2009; Zhang \& Epley, 17 2009). In an exceptional study, Flynn and Adams (2009) demonstrated that gift givers tend to 18 expect that the cost, rather than the benefit, determines the gratitude of gift recipients, whereas the recipients' gratitude was in fact determined by the benefits accruing from the gift.

20 Nevertheless, how the costs and benefits of prosocial behaviors independently impact third-party

21 observers' evaluation of prosocial actors has not been systematically investigated. 


\section{COST AND BENEFIT OF PROSOCIAL BEHAVIOR}

1 individual differences: warmth and competence (e.g., Fiske, Cuddy, \& Glick, 2007; Fiske,

2 Cuddy, Glick, \& Xu, 2002). The present study also focused on these fundamental dimensions in

3 examining the effects of costs and benefits of prosocial behaviors on impressions of actors.

4 Although a few studies have investigated the relationship between prosocial behaviors and these

5 dimensions (Klein \& Epley, 2014), it is not known which aspects of prosocial behaviors (i.e.,

6 cost and benefit) influence the perception of warmth and competence. These distinctions are

7 important because, as we explain below, it is expected that the two aspects of prosocial behaviors

8 may be differentially associated with perceived warmth and competence (cf. Klein \& Epley,

$92014)$

In the dimension of warmth, it is expected for both the cost and benefit of prosocial

11 behavior to be positively correlated with the actor's warmth: other things (including competence)

12 being equal, the warmer an individual is, he/she is more willing to incur greater cost for someone

13 else, and brings about more benefit to the beneficiaries. Consistent with this natural reasoning,

14 major psychological causes of prosocial behaviors include warmth-related emotion (e.g.,

15 empathy; Batson, 2011) and personality (e.g., agreeableness; Habashi, Graziano, \& Hoover,

16 2016). Regarding the actors' costs, many economic games, which are used to assess prosocial

17 tendencies, incentivize "not acting in a prosocial manner"- (e.g., Camerer, 2003) - it is assumed

18 that actors would not incur any costs without other-regarding preferences (i.e., warmth). In other

19 words, the cost of prosocial behavior reflects the strength of warmth. Regarding benefit to

20 beneficiaries, most people consider that the goals of others' prosocial acts are contributinge to

21 other's benefit (Carlson \& Zaki, 2019; Gebauer, Sedikides, Leary, \& Asendorpf, 2015).

22 Therefore, we predicted that both cost and benefit of prosocial behaviors are positively correlated

23 with perceived warmth. 


\section{COST AND BENEFIT OF PROSOCIAL BEHAVIOR}

In the domain of competence, the effects of cost and benefit of prosocial behavior on

perceived competence may not be monolithic, and thus more complicated. Although it is reasonable to assume the positive correlation between competence and benefit (i.e., the more competent is an individual, he/she can bring about greater benefit with a fixed amount of cost), the game theoretic reasoning leads us to assume the negative correlation between competence and cost (Gintis, Smith, \& Bowles, 2001). For example, in an emergency situation, less competent members of a rescue crew may need to put forth more physical effort and take longer to save a single victim than more competent members. In reality, however, this negative correlation might not hold. Consider certain types of prosocial behavior that might fail to produce benefit (e.g., Bolger \& Amarel, 2007; Feeney, 2004): for example, advice from prosocial actors may or may not be useful for the recipients. In such cases, competence is positively correlated with benefit — a socially competent actor can provide useful advice. However, the cost (e.g., the time and effort that the actor put forth giving the advice) may not be correlated with competence - competent individuals may be able to provide useful advice (i.e., benefit) with little effort (i.e., high benefit and low cost), whereas incompetent individuals may fail to provide useful advice no matter how long they keep thinking-(i.e., low benefit and high cost). Therefore, cost may not correlate with perceived competence, or if cost and perceived competence were ever related, it should be a negative, rather than a positive, relationship. In sum, different predictions can be formed according to costs and benefits: the size of the benefit (but not cost) would enhance perceived competence.

\section{The Current Study}

We conducted a set of three vignette studies (Studies 1, 2a, and 2b) to investigate the effects of cost and benefit on the perceptions of warmth and competence. We hypothesized that 


\section{COST AND BENEFIT OF PROSOCIAL BEHAVIOR}

1 both the costs and benefits of prosocial behaviors will enhance perceived warmth, while the

2 benefits of prosocial behaviors, and not the costs, will enhance perceived competence. Study 1

3 employed a 2 (cost of the prosocial behaviors: high vs. low) $\times 2$ (benefit: high vs. low) within-

4 participant factorial design, in which participants evaluated fictitious generous individuals in

5 terms of warmth, competence, likeability as a friend, likeability as a coworker, and willingness to

6 help. In Studies $2 \mathrm{a}$ and $2 \mathrm{~b}$, to confirm the robustness of the findings of Study 1, we manipulated

7 the cost (Study 2a) and benefit (Study 2b) separately.

\section{Study 1}

In Study 1, we independently manipulated the costs and benefits of prosocial behaviors.

11 Participants read a series of vignettes, each depicting a prosocial behavior, and rated their

12 perceived warmth and competence of the actor. We hypothesized that both the costs and benefits

13 of prosocial behaviors would enhance perceived warmth, while only the benefits of prosocial

14 behaviors would enhance perceived competence.

As auxiliary measures, we also examined how the costs and benefits of prosocial

16 behaviors would influence perceived likeability of the prosocial individual as a friend, perceived

17 likeability as a coworker, and willingness to help the prosocial individual (when he/she is in

18 need). We predicted that both the cost and benefit would be positively associated with the two

19 warmth-relevant items (i.e., likeability as a friend and willingness-to-help), whereas only the

20 benefit would be positively associated with the competence-relevant item (i.e., likeability as a

21 coworker).

22 Methods

Participants and design. We recruited 280 participants (143 men, 137 women) through 


\section{COST AND BENEFIT OF PROSOCIAL BEHAVIOR}

1 a Japanese crowdsourcing service, CrowdWorks. The average age of the participants was 39.2

2 years $(S D=9.32$; range: $20-59)$. Sample size was determined before data collection. The study

3 used a 2 (Cost: High vs. Low) $\times 2$ (Benefit: High vs. Low) within-participant factorial design. A

4 sensitivity power analysis using Power ANalysis for GEneral Anova designs (PANGEA;

5 (Westfall, 2016) indicated that our final sample size $(N=274)$ had $80 \%$ power to detect a

6 medium-sized main effect of $d=.52$ with $\alpha=.05$. The study was approved by the ethics

$7 \quad$ committee of the third author's institution.

Vignettes. Participants read and rated 48 vignettes. We prepared 12 settings and each setting had four $(2[\operatorname{cost}] \times 2$ [benefit] $)$ versions. Therefore, each vignette included both the cost and benefit information. An example setting is as follows:

[A protagonist] heard that his/her close, male/female colleague had failed in his/her job.

For each evaluation session, such a setting scenario was followed by additional information

corresponding to one of the 2 (Cost) $\times 2$ (Benefit) conditions. For the above setting, one of the

following pieces of information was provided to manipulate the cost:

For the above setting, one of the following pieces of information was provided to manipulate the benefit: him/her some advice. (High Cost)

[The protagonist] spent a few minutes listening to the colleague's complaints and giving him/her some advice. (Low Cost)

His/her advice helped the colleague a lot because it was appropriate for the colleague's situation. (High Benefit)

His/her advice did not help the colleague because it was slightly irrelevant. (Low 


\section{COST AND BENEFIT OF PROSOCIAL BEHAVIOR}

1

\section{Benefit)}

We matched participants' own gender with the gender of the protagonist and the

Therefore, all participants assumed that the described interaction occurred between two individuals whose gender was same as their own.

The vignettes included various situations such as gift-giving, charitable donations, and helping to clean up. The 12 settings were adapted from two questionnaires to measure prosocial behaviors, one of which were developed based on a pilot study on real-world prosocial behaviors (Johnson et al., 1989; Oda et al., 2013). We associated various types of costs (e.g., effort, time, or money) and benefits (e.g., physical, financial, or psychological) with the 12 settings. Therefore, we think the general themes of our 12 settings and the following cost and benefit scenarios retain external validity. All vignettes can be found at https://osf.io/hp6kq/?view_only=38ab48e33eba4cf8b4592257e46ac174

The order of the 48 vignettes were semi-randomized in the following manner. The 48 vignettes were first divided into four blocks, each of which contained the 12 settings. Within each block, the 12 settings were followed by one of the four (cost $\times$ benefit) conditions. For each participant, the order of blocks and the order of the 12 settings in each block were randomized. Therefore, the order of the 48 vignettes was mostly randomized except that the 12 settings were distributed sparsely through the 48 trials.

Measures. After reading each vignette, participants rated their perceived cost and benefit of the behavior on a 7-point scale $(1=$ strongly disagree, $7=$ strongly agree $)$ as manipulation checks. Subsequently, they rated perceived warmth with two items (good-natured and warm; $r=.87$ ) and perceived competence with two items (competent and capable; $r=.94)$ 


\section{COST AND BENEFIT OF PROSOCIAL BEHAVIOR}

1 on a 7 -point scale $(1=$ not at all, $7=$ extremely $)$. These items were adapted from Fiske et al.

2 (2002). The two warmth items and two competence items were aggregated to obtain single

3 scores of warmth and competence, respectively. In addition, participants rated the likeability of

4 the protagonist as a friend, the likeability as a coworker, and their willingness to help the protagonist if he/she is in need on a 7 -point scale $(1=$ strongly disagree, $7=$ strongly agree $)$.

After the 48 vignettes, an attention check task was included. Participants were presented the four trait items included in the study (i.e., good-natured, warm, competent, and capable) and one irrelevant item (i.e., tall) and asked to select the item that was not used to evaluate the

9 protagonists. Based on this attention check, data from six participants were discarded, resulting in a final sample comprised of 274 Japanese individuals aged 20-59 years $(M=39.2, S D=9.32$;

11141 men, 133 women).

\section{Results and Discussion}

The descriptive statistics are shown in Table 1 (for the descriptive statistics per vignette,

14 see Tables S1-S7). The correlation between warmth and competence was .42. For each variable,

15 we conducted linear mixed model (LMM) analyses with participants and vignettes as random

16 effects and two dummy variables of cost $($ Low $=-0.5$, High $=0.5)$ and benefit $($ Low $=-0.5$, High

$17=0.5)$ as fixed effects. The results of the random effect aspects are reported only in

18 Supplementary Materials (Tables S24-S30). We also entered a dummy-coded variable

19 representing gender $($ Men $=-0.5$, Women $=0.5)$ as a control variable because the protagonist's

20 gender in the vignettes differed according to the participant's gender (we conducted the

21 comparable analyses excluding gender and confirmed that the exclusion of gender did not alter

22 the reported pattern of significance; see Tables S14-S16). In addition, although we tested the

23 interaction between cost and benefit, it was not significant (see Tables S12-S13). These analyses 
COST AND BENEFIT OF PROSOCIAL BEHAVIOR

1 were conducted using R 3.5.1 with lme4 (Bates, Mächler, Bolker, \& Walker, 2015), lmerTest

2 Table 1. Means and SDs for Each Scale in Study $1(N=274)$.

\begin{tabular}{|c|c|c|c|c|c|c|c|c|}
\hline \multirow[b]{3}{*}{ Measures } & \multicolumn{4}{|c|}{ High Benefit } & \multicolumn{4}{|c|}{ Low Benefit } \\
\hline & \multicolumn{2}{|c|}{ High Cost } & \multicolumn{2}{|c|}{ Low Cost } & \multicolumn{2}{|c|}{ High Cost } & \multicolumn{2}{|c|}{ Low Cost } \\
\hline & $M$ & $S D$ & $M$ & $S D$ & $M$ & $S D$ & $M$ & $S D$ \\
\hline \multicolumn{9}{|l|}{ Manipulation Check } \\
\hline Perceived Cost & 6.06 & 0.93 & 5.33 & 1.01 & 5.93 & 0.80 & 5.16 & 0.82 \\
\hline Perceived Benefit & 6.35 & 0.55 & 6.23 & 0.55 & 2.67 & 0.80 & 2.72 & 0.79 \\
\hline \multicolumn{9}{|l|}{ Impression } \\
\hline Perceived Warmth & 6.39 & 0.57 & 6.04 & 0.63 & 5.96 & 0.72 & 5.53 & 0.71 \\
\hline Perceived Competence & 5.73 & 0.75 & 5.76 & 0.65 & 3.38 & 0.90 & 3.47 & 0.84 \\
\hline \multicolumn{9}{|l|}{ Auxiliary Variables } \\
\hline Likeability as a Friend & 5.71 & 0.81 & 5.57 & 0.72 & 4.62 & 1.01 & 4.47 & 0.91 \\
\hline \multicolumn{9}{|l|}{ Likeability as a } \\
\hline & 5.63 & 0.82 & 5.62 & 0.73 & 3.93 & 1.01 & 3.93 & 0.93 \\
\hline \multicolumn{9}{|l|}{ Coworker } \\
\hline Willingness-to-Help & 5.83 & 0.77 & 5.65 & 0.74 & 4.98 & 0.94 & 4.79 & 0.92 \\
\hline
\end{tabular}

Note: All scales range from 1 to 7.

4

5 (Kuznetsova, Brockhoff, \& Christensen, 2017), and sjstats (Lüdecke, 2019) packages. Following

6 the recommendations of Barr, Levy, Scheepers, and Tily (2013), we adapted a maximal random

7 effects structure for model specification (see also Judd, Westfall, \& Kenny, 2017). However, the

8 model with perceived benefit as the dependent variable did not converge. In this case, we

9 adapted a no-random-correlation model (Barr et al., 2013). 


\section{COST AND BENEFIT OF PROSOCIAL BEHAVIOR}

Manipulation checks. We first conducted LMM analyses on perceived cost and benefit

2 (Tables S12, S24, and S25). Overall, the manipulations were successful: participants perceived

3 the prosocial behaviors as being more costly in the high cost than in the low cost condition $(B=$

$4 \quad 0.75,95 \%$ CI $[0.63,0.88], \beta=.31, t(20.24)=11.90, p<.001)$. The effect of cost manipulation on

5 perceived benefit was not significant $(B=0.04,95 \%$ CI $[-0.01,0.08], \beta=.01, t(11.61)=1.61, p$

$6=.135)$. Participants also perceived prosocial behaviors as being more beneficial in the high

7 benefit than in the low benefit condition $(B=3.60,95 \%$ CI $[3.27,3.93], \beta=.85, t(14.39)=$

$821.51, p<.001)$. Unexpectedly, participants perceived prosocial behaviors as being more costly

9 in the high benefit than in the low benefit condition $(B=0.15,95 \% \mathrm{CI}[0.05,0.25], \beta=.06$,

$t(56.96)=2.92, p=.005)$. However, this unexpected effect of the benefit manipulation on

11 perceived cost was much smaller than its effect on perceived benefit ( $\beta=.85$ vs. .06).

Warmth and competence. Confirming the success in the manipulations of cost and

13 benefit, we conducted LMM analyses with perceived warmth and competence as dependent

14 variables (Tables 2, S26-S27). The effects of cost and benefit on perceived warmth were

15 significant. Participants found the protagonist as a warmer person in the high cost than in the low

16 cost condition $(B=0.39,95 \% \mathrm{CI}[0.29,0.49], \beta=.20, t(15.78)=7.70, p<.001)$, as well as a

17 warmer person in the high benefit than in the low benefit condition $(B=0.47,95 \%$ CI $[0.35$,

$180.58], \beta=.24, t(16.18)=8.07, p<.001)$.

Regarding perceived competence, only the effect of benefit was significant. Participants

20 found the protagonist as a more competent person in the high benefit than in the low benefit

21 condition $(B=2.32,95 \%$ CI $[2.03,2.61], \beta=.70, t(15.31)=15.67, p<.001)$. The effect of cost

22 on perceived competence was not significant $(B=-0.06,95 \%$ CI $[-0.18,0.06], \beta=-.02, t(11.90)$

$23=-1.04, p=.320)$. 
COST AND BENEFIT OF PROSOCIAL BEHAVIOR

To assess the robustness of these results, we conducted the comparable analyses

Perceived Warmth (Study 1)

\begin{tabular}{|c|c|c|c|c|c|c|c|}
\hline Measures & $B$ & $95 \% \mathrm{CI}$ & $\beta$ & $S E$ & $d f$ & $t$ & $p$ \\
\hline (Intercept) & 5.98 & {$[5.87,6.10]$} & & 0.06 & 26.18 & 102.30 & $<.001$ \\
\hline SEX (-0.5: Male, 0.5: Female) & 0.06 & {$[-0.07,0.18]$} & .03 & 0.07 & 272.00 & 0.86 & .391 \\
\hline Cost (-0.5: Low, 0.5: High) & 0.39 & {$[0.29,0.49]$} & .20 & 0.05 & 15.78 & 7.70 & $<.001$ \\
\hline Benefit (-0.5: Low, 0.5: High) & 0.47 & {$[0.35,0.58]$} & .24 & 0.06 & 16.18 & 8.07 & $<.001$ \\
\hline \multirow[t]{2}{*}{ Cost*Benefit } & -0.07 & {$[-0.17,0.02]$} & -.02 & 0.05 & 11.84 & -1.54 & .150 \\
\hline & \multicolumn{7}{|c|}{ Perceived Competence (Study 1) } \\
\hline Measures & $B$ & $95 \% \mathrm{CI}$ & $\beta$ & $S E$ & $d f$ & $t$ & $p$ \\
\hline (Intercept) & 4.59 & {$[4.42,4.75]$} & & 0.08 & 16.03 & 54.59 & $<.001$ \\
\hline SEX (-0.5: Male, 0.5: Female) & 0.08 & {$[-0.05,0.21]$} & .02 & 0.07 & 272.01 & 1.20 & .230 \\
\hline Cost (-0.5: Low, 0.5: High) & -0.06 & {$[-0.18,0.06]$} & -.02 & 0.06 & 11.90 & -1.04 & .320 \\
\hline Benefit (-0.5: Low, 0.5: High) & 2.32 & {$[2.03,2.61]$} & .70 & 0.15 & 15.31 & 15.67 & $<.001$ \\
\hline Cost ${ }^{*}$ Benefit & 0.07 & {$[-0.19,0.33]$} & .01 & 0.13 & 11.09 & 0.55 & .596 \\
\hline
\end{tabular}

4

5 including perceived cost and benefit, instead of the dummy-coded cost and benefit variables, as

6 the predictor variables. The results were consistent with the hypotheses: both perceived cost and

7 benefit predicted perceived warmth, whereas only perceived benefit (not perceived cost)

8 predicted perceived competence (Tables S17, S38-S39). 


\section{COST AND BENEFIT OF PROSOCIAL BEHAVIOR}

1 likeability as a coworker, and willingness-to-help (Tables S13, S28-S30). Participants perceived

the protagonist as being more likeable as a friend in the high cost than in the low cost condition $(B=0.14,95 \%$ CI $[0.07,0.22], \beta=.05, t(17.61)=3.76, p=.001)$. Participants also perceived the protagonist as being more likeable as a friend in the high benefit than in the low benefit condition $(B=1.10,95 \%$ CI $[0.88,1.31], \beta=.41, t(15.01)=9.99, p<.001)$.

As for likeability as a coworker, only the effect of benefit was significant. Participants perceived the protagonist as being more likeable as a coworker in the high benefit than in the low benefit condition $(B=1.69,95 \%$ CI $[1.40,1.98], \beta=.55, t(14.40)=11.39, p<.001)$. However, the effect of cost on likeability as a coworker was not significant $(B=0.01,95 \%$ CI [-0.07, 0.09], $\beta=.00, t(14.74)=0.14, p=.889)$.

As for willingness to help, participants reported greater willingness to help the protagonist in the high cost than in the low cost condition $(B=0.18,95 \% \mathrm{CI}[0.11,0.26], \beta$ $=.08, t(15.87)=4.60, p<.001)$ and greater willingness to help the protagonist in the high benefit than in the low benefit condition $(B=0.85,95 \% \mathrm{CI}[0.69,1.01], \beta=.36, t(18.78)=$ $10.44, p<.001)$

In Study 1, we investigated the associations between the costs and benefits of prosocial behaviors and the perceived warmth and competence of the actor. In line with our hypotheses, both the costs and benefits of prosocial behaviors enhanced perceived warmth, whereas only the benefit enhanced perceived competence. The auxiliary analyses confirmed this pattern: both the cost and benefit increased perceived likeability of the prosocial individual as a friend and participants' willingness to help the individual. By contrast, only the benefits of prosocial behaviors increased the perceived likeability of the prosocial individual as a coworker.

In Study 1, participants were exposed to a series of vignettes in which both the cost and 


\section{COST AND BENEFIT OF PROSOCIAL BEHAVIOR}

1 benefit were systematically manipulated. This design may be associated with a problem of demand characteristics - it might have unwittingly urged participants to consider the effects of cost and benefit separately. Therefore, in Studies $2 \mathrm{a}$ and $2 \mathrm{~b}$, we manipulated only one of the two aspects of prosocial behaviors to avoid unwittingly leading participants to consider the two aspects separately.

\section{Studies $2 \mathrm{a}$ and $\mathbf{2 b}$}

In Studies $2 \mathrm{a}$ and $2 \mathrm{~b}$, participants were asked to rate their perception of the protagonist based on either the level of cost (Study 2a) or benefit (Study 2b). Unlike in Study 1 where the perceptions of warmth and competence were measured by two items each, we increased the number of warmth/competence items to more comprehensively measure each construct.

\section{Methods}

Participants and design. Participants were recruited through a Japanese crowdsourcing service, Lancers. Study 2a contained 99 participants whose average age was 38.9 years $(S D=$ 8.77 ; range $=21-59 ; 56$ men, 43 women). Study 2 b contained 101 participants whose average age was 41.7 years $(S D=8.45$; range $=21-59 ; 57$ men, 44 women $)$. Sample size was determined before data collection. Each experiment manipulated only one aspect of prosocial behavior (cost and benefit in Studies 2a and 2b, respectively) as a within-participant condition. A series of sensitivity power analyses using PANGEA (Westfall, 2016) indicated that the final sample sizes of both studies ( $N=99$ and 101 for Studies $2 \mathrm{a}$ and $2 \mathrm{~b}$, respectively) had $80 \%$ power to detect a medium main effect of $d=.65$ and .64 with $\alpha=.05$. This study was approved by the ethics committee of the third author's institution.

Vignettes. The vignettes were similar to the ones used in Study 1. However, the 


\section{COST AND BENEFIT OF PROSOCIAL BEHAVIOR}

1 description of the benefit accruing from the protagonist's behavior was removed from each vignette in Study 2a. In Study 2b, the descriptions of the cost of prosocial behaviors were removed from the vignettes.

In both studies, the order of the 24 vignettes was semi-randomized in the same manner as in Study 1. In Studies $2 \mathrm{a}$ and $2 \mathrm{~b}$, the 24 vignettes were divided into two blocks, instead of four blocks.

Measures. The manipulation check items were identical with those in Study 1.

However, in Study 2, we removed the three auxiliary variables to increase the number of items of the main two variables (perceived warmth and competence). Perceived warmth was assessed with the following four items, which were adapted from Fiske et al.'s (2002) study: goodnatured, warm, sincere, and well-intentioned: Cronbach's $\alpha$ coefficients were .93 and .93 in Studies $2 \mathrm{a}$ and $2 \mathrm{~b}$, respectively. Perceived competence was assessed with the following four items: competent, capable, confident, and intelligent: Cronbach's $\alpha$ coefficients were .89 and .90 in Studies $2 \mathrm{a}$ and $2 \mathrm{~b}$, respectively. All items were rated on a 7 -point scale $(1=$ not at all, $7=$ extremely). Although we administered the same attention check task as in Study 1, no participants were discarded due to the attention check task in Studies $2 \mathrm{a}$ and $2 \mathrm{~b}$.

\section{Results and Discussion}

The descriptive statistics are shown in Table 3 (for the descriptive statistics per vignettes, see Tables S8-S11). The correlations between warmth and competence were .59 and .51 in Study $2 \mathrm{a}$ and 2b, respectively. Using the same R packages as in Study 1, we conducted LMM analyses with participants and vignettes as random effects and the dummy-coded variable of cost $($ Low $=-0.5$, High $=0.5$; Study $2 \mathrm{a})$ or benefit $($ Low $=-0.5$, High $=0.5 ;$ Study $2 b)$ as a

$$
\text { fixed effect. We also entered a dummy-coded variable of gender }(\text { Men }=-0.5 \text {, Women }=0.5) \text { in }
$$


COST AND BENEFIT OF PROSOCIAL BEHAVIOR

1 the model as a control variable.

2 Table 3. Means and SDs for Each Scale in Study $2 a(N=99)$ and $2 b(N=101)$.

\begin{tabular}{|c|c|c|c|c|c|c|c|c|}
\hline \multirow[b]{3}{*}{ Measures } & \multicolumn{4}{|c|}{ Study $2 \mathrm{a}$} & \multicolumn{4}{|c|}{ Study $2 b$} \\
\hline & \multicolumn{2}{|c|}{ High Cost } & \multicolumn{2}{|c|}{ Low Cost } & \multicolumn{2}{|c|}{ High Benefit } & \multicolumn{2}{|c|}{ Low Benefit } \\
\hline & $M$ & $S D$ & $M$ & $S D$ & $M$ & $S D$ & $M$ & $S D$ \\
\hline \multicolumn{9}{|l|}{ Manipulation Check } \\
\hline Perceived Cost & 5.84 & 1.02 & 4.94 & 0.94 & 5.64 & 0.87 & 5.56 & 0.68 \\
\hline Perceived Benefit & 5.45 & 0.80 & 5.13 & 0.57 & 6.29 & 0.64 & 2.83 & 0.67 \\
\hline \multicolumn{9}{|l|}{ Impression } \\
\hline Perceived Warmth & 6.00 & 0.69 & 5.56 & 0.63 & 6.16 & 0.79 & 5.73 & 0.79 \\
\hline Perceived Competence & 4.95 & 0.76 & 4.83 & 0.63 & 5.45 & 0.79 & 3.91 & 0.57 \\
\hline
\end{tabular}

Note: All scales range from 1 to 7.

Manipulation check (Study 2a). LMM analyses on perceived cost and benefit showed that the manipulation of cost significantly increased perceived cost and benefit (Tables S19, S41S42). Participants perceived the prosocial behavior as being more costly in the high cost than in the low cost condition $(B=0.90,95 \%$ CI $[0.73,1.07], \beta=.35, t(30.40)=10.50, p<.001)$.

Unexpectedly, participants perceived the prosocial behavior as being more beneficial, too, in the high cost than in the low cost condition $(B=0.32,95 \%$ CI $[0.14,0.49], \beta=.14, t(15.61)=3.48$, $p=.003)$. However, the effect of cost on perceived benefit was smaller than its effect on perceived cost $(\beta=.35$ vs. .14).

Manipulation check (Study 2b). LMM analyses on perceived cost and benefit showed that the manipulation of benefit increased only perceived benefit (Tables S19, S43-S44). 


\section{COST AND BENEFIT OF PROSOCIAL BEHAVIOR}

1 Participants perceived the prosocial behavior as being more beneficial in the high benefit than in

the low benefit condition $(B=3.46,95 \%$ CI $[3.01,3.91], \beta=.85, t(17.05)=15.06, p<.001)$.

The manipulation of benefit did not affect the perception of $\operatorname{cost}(B=0.07,95 \%$ CI $[-0.05,0.20]$, $\beta=.03, t(54.92)=1.14, p=.260)$.

Effect of cost on warmth and competence (Study 2a). We then conducted a series of LMM analyses on perceived warmth and competence (Tables 4, S45-S46). Participants found the protagonist as a warmer person in the high cost than in the low cost condition $(B=0.44,95 \% \mathrm{CI}$ $[0.28,0.59], \beta=.23, t(16.22)=5.60, p<.001)$. Confirming Study 1 , the effect of cost on perceived competence was not significant $(B=0.12,95 \%$ CI $[-0.13,0.37], \beta=.06, t(12.87)=0.93, p=.371)$. The comparable analyses including the perceived cost variable, instead of dummy-coded cost variable, confirmed these results (Tables S22, S57-S58)

Effect of benefit on warmth and competence (Study 2b). A series of LMM analyses on perceived warmth and competence showed that the effects of benefit on perceived warmth and competence were significant (Tables 4, S47-S48). Participants found the protagonist as a warmer person $(B=0.43,95 \%$ CI $[0.29,0.57], \beta=.22, t(21.52)=6.16, p<.001)$ and a more competent person $(B=1.54,95 \%$ CI $[1.24,1.84], \beta=.62, t(17.54)=10.05, p<.001)$ in the high benefit than in the low benefit condition. The comparable analyses including the perceived benefit variable, instead of dummy-coded benefit variables, confirmed these results (Tables S22, S59-S60)

In Studies $2 \mathrm{a}$ and $2 \mathrm{~b}$, we manipulated only one aspect of prosocial behaviors (i.e., either cost or benefit) to avoid any suggestion that we were interested in differentiating the effects of costs and benefits of prosocial behaviors on impression of prosocial individuals. The results of these two studies confirmed the results of Study 1: the costs of prosocial behaviors only enhanced perceived warmth, while the benefits of prosocial behaviors enhanced both perceived 
COST AND BENEFIT OF PROSOCIAL BEHAVIOR

1 warmth and competence. 
Running Head: COST AND BENEFIT OF PROSOCIAL BEHAVIOR

1 Table 4. Fixed Effects of Linear Mixed Model Analyses on Perceived Warmth and Competence (Studies 2a and 2b).

\begin{tabular}{|c|c|c|c|c|c|c|c|c|c|c|c|c|c|c|}
\hline \multirow[b]{2}{*}{ Measures } & \multicolumn{7}{|c|}{ Perceived Warmth (Study 2a) } & \multicolumn{7}{|c|}{ Perceived Warmth (Study 2b) } \\
\hline & $B$ & $95 \% \mathrm{CI}$ & $\beta$ & $S E$ & $d f$ & $t$ & $p$ & $B$ & $95 \% \mathrm{CI}$ & $\beta$ & $S E$ & $d f$ & $t$ & $p$ \\
\hline (Intercept) & 5.80 & {$[5.62,5.98]$} & & 0.09 & 32.74 & 62.70 & $<.001$ & 5.94 & {$[5.75,6.13]$} & & 0.10 & 54.83 & 60.59 & $<.001$ \\
\hline SEX (-0.5: Male, 0.5: Female) & 0.26 & {$[0.01,0.50]$} & .14 & 0.12 & 97.00 & 2.07 & .041 & -0.07 & {$[-0.38,0.23]$} & -.04 & 0.15 & 99.00 & -0.48 & .629 \\
\hline Cost (-0.5: Low, 0.5: High) & 0.44 & {$[0.28,0.59]$} & .23 & 0.08 & 16.22 & 5.60 & $<.001$ & & & & & & & \\
\hline \multirow[t]{2}{*}{ Benefit (-0.5: Low, 0.5: High) } & & & & & & & & 0.43 & {$[0.29,0.57]$} & .22 & 0.07 & 21.52 & 6.16 & $<.001$ \\
\hline & \multicolumn{7}{|c|}{ Perceived Competence (Study 2a) } & \multicolumn{7}{|c|}{ Perceived Competence (Study 2b) } \\
\hline Measures & $B$ & $95 \% \mathrm{CI}$ & $\beta$ & $S E$ & $d f$ & $t$ & $p$ & $B$ & $95 \% \mathrm{CI}$ & $\beta$ & $S E$ & $d f$ & $t$ & $p$ \\
\hline (Intercept) & 4.91 & {$[4.69,5.12]$} & & 0.11 & 24.74 & 44.88 & $<.001$ & 4.68 & {$[4.51,4.85]$} & & 0.09 & 31.04 & 53.76 & $<.001$ \\
\hline SEX (-0.5: Male, 0.5: Female) & 0.21 & {$[-0.04,0.46]$} & .10 & 0.13 & 97.00 & 1.66 & .100 & 0.02 & {$[-0.20,0.23]$} & .01 & 0.11 & 99.00 & 0.15 & .883 \\
\hline Cost (-0.5: Low, 0.5: High) & 0.12 & {$[-0.13,0.37]$} & .06 & 0.13 & 12.87 & 0.93 & .371 & & & & & & & \\
\hline Benefit (-0.5: Low, 0.5: High) & & & & & & & & 1.54 & {$[1.24,1.84]$} & .62 & 0.15 & 17.54 & 10.05 & $<.001$ \\
\hline
\end{tabular}

2 
Running Head: COST AND BENEFIT OF ALTRUISM

\section{General Discussion}

Although previous studies have repeatedly shown that prosocial behaviors confers a positive reputation on individuals (e.g., Barclay, 2004; Hardy \& Van Vugt, 2006; Willer, 2009), the different effects of the cost and benefit of prosocial behaviors have not been systematically examined. The present three studies investigated the effects of the costs and benefits of prosocial behaviors on the two dominant dimensions of person perception-warmth and competence (Fiske et al., 2007; Fiske et al., 2002). The results showed that cost enhanced perceived warmth, whereas benefit enhanced both perceived warmth and competence. These associations were observed regardless of whether the cost and benefit were manipulated simultaneously (Study 1) or separately (Studies $2 \mathrm{a}$ and $2 \mathrm{~b}$ ).

The present study revealed clear evidence that the cost and benefit of prosocial behaviors are differently accounted for in person perception, especially in determining the benefactor's competence. However, this study has several limitations. First, participants did not observe real behavior, which should be examined in future studies. Second, the present study adopted within-participant factorial design; therefore, it might have been easier for participants to compare the high and low cost/benefit. If these factors were manipulated as betweenparticipants factors, the effect sizes might have been smaller. Third, this study exclusively focused on the third-party perspective and did not consider the beneficiaries' perceptions of the benefactors. However, it is possible that third-party observers and beneficiaries of altruistic behaviors disagree on how they evaluate prosocial individuals (cf. Flynn \& Adams, 2009; Zhang \& Epley, 2009). Fourth, the present study focused only on warmth and competence. However, some studies have shown that morality is a distinct dimension from warmth and competence, and more central in person perception (e.g., Goodwin, Piazza, \& Rozin, 2014). Thus, future studies 


\section{COST AND BENEFIT OF ALTRUISM}

1 need to include measures of perceived morality of the prosocial actors. Fifth, the present studies

2 did not distinguish the objective benefits and how well the benefits are matched to the needs of

3 the recipients. Future studies need to independently manipulate these factors. Sixth, in the

4 vignettes used in the present study, the size of benefit was, at least partly, related to the

5 protagonists' competence. However, the benefit size is not solely determined by the actors'

6 competence (e.g., when actors happen to know information desperately needed by someone).

7 Whether the benefit size would also enhance perceived competence in such cases is an

8 interesting empirical question. Finally, it may be worth investigating how observers' evaluations

9 influence the actors' prosocial behavior.

Although the present study was conducted in the context of person perception, it is of

11 great relevance to the growing interest in effective altruism movement (e.g., Berman, Barasch,

12 Levine, \& Small, 2018; MacAskill, 2015): the movement to promote charitable behaviors

13 conducted in an effective way (i.e., maximizing benefits at constant costs). The present study,

14 which distinguished the cost and benefit of prosocial behaviors, can be readily modified and

15 extended to this context: for example, a person who donates to more effective charities might be

16 seen as a warmer and more competent person. As it is important to efficiently promote the

17 greater good, separate assessments of the cost and benefit aspects of prosocial behaviors can

18 deepen our understanding of prosocial behaviors. 


\section{COST AND BENEFIT OF ALTRUISM}

\section{References}

Barasch, A., Levine, E. E., Berman, J. Z., \& Small, D. A. (2014). Selfish or selfless? On the signal value of emotion in altruistic behavior. Journal of Personality and Social Psychology, 107, 393-413. doi:10.1037/a0037207

Barclay, P. (2004). Trustworthiness and competitive altruism can also solve the "tragedy of the commons". Evolution and Human Behavior, 25, 209-220. doi:10.1016/j.evolhumbehav.2004.04.002

Barr, D. J., Levy, R., Scheepers, C., \& Tily, H. J. (2013). Random effects structure for confirmatory hypothesis testing: Keep it maximal. Journal of Memory and Language, 68, 255-278. doi:10.1016/j.jml.2012.11.001

Bates, D., Mächler, M., Bolker, B., \& Walker, S. (2015). Fitting Linear Mixed-Effects Models Usinglme4. Journal of Statistical Software, 67. doi:10.18637/jss.v067.i01

Batson, C. D. (2011). Altruism in humans. USA: Oxford University Press.

Berman, J. Z., Barasch, A., Levine, E. E., \& Small, D. A. (2018). Impediments to Effective Altruism: The Role of Subjective Preferences in Charitable Giving. Psychol Sci, 29, 834844. doi:10.1177/0956797617747648

Bolger, N., \& Amarel, D. (2007). Effects of social support visibility on adjustment to stress: experimental evidence. Journal of Personality and Social Psychology, 92, 458-475. doi:10.1037/0022-3514.92.3.458

Camerer, C., F. (2003). Behavioral game theory: Experiments in strategic interaction. Princeton, NJ: Princeton University Press.

Carlson, R. W., \& Zaki, J. (2018). Good deeds gone bad: Lay theories of altruism and selfishness. Journal of Experimental Social Psychology, 75. 


\section{COST AND BENEFIT OF ALTRUISM}

1

doi:10.1016/j.jesp.2017.11.005

Carlson, R. W., \& Zaki, J. (2019). Belief in altruistic motives predicts prosocial actions and inferences. doi:10.31234/osf.io/sa6q8

Dorsch, M. J., \& Kelley, S. W. (1994). An investigation into the Intentions of Purchasing Executives to Reciprocate Vendor Gifts. Journal of the Academy of Marketing Science, 22, 315-327. doi:10.1177/0092070394224001

Duval, S., Duval, V. H., \& Neely, R. (1979). Self-focus, felt responsibility, and helping behavior. Journal of Personality and Social Psychology, 37, 1769-1778. doi:10.1037/00223514.37.10.1769

Feeney, B. C. (2004). A secure base: responsive support of goal strivings and exploration in adult intimate relationships. Journal of Personality and Social Psychology, 87, 631-648. doi:10.1037/0022-3514.87.5.631

Fehr, E., \& Fischbacher, U. (2003). The nature of human altruism. Nature, 425, 785-791. doi:10.1038/nature02043

Fiske, S. T., Cuddy, A. J., \& Glick, P. (2007). Universal dimensions of social cognition: warmth and competence. Trends in Cognitive Sciences, 11, 77-83. doi:10.1016/j.tics.2006.11.005

Fiske, S. T., Cuddy, A. J., Glick, P., \& Xu, J. (2002). A model of (often mixed) stereotype content : competence and warmth respectively follow from perceived status and competition. Journal of Personality and Social Psychology, 82, 878-902. doi: $10.1037 / / 0022-3514.82 .6 .878$

Flynn, F. J., \& Adams, G. S. (2009). Money can’t buy love: Asymmetric beliefs about gift price and feelings of appreciation. Journal of Experimental Social Psychology, 45, 404-409. doi:10.1016/j.jesp.2008.11.003 


\section{COST AND BENEFIT OF ALTRUISM}

Gebauer, J. E., Sedikides, C., Leary, M. R., \& Asendorpf, J. B. (2015). Lay beliefs in true altruism versus universal egoism. In C. B. Miller, R. M. Furr, A. Knobel, \& W. Fleeson (Eds.), Character: New Directions from Philosophy, Psychology, and Theology (pp. 7599). Oxford, UK: Oxford University Press.

Gintis, H., Smith, E. A., \& Bowles, S. (2001). Costly signaling and cooperation. Journal of theoretical biology, 213, 103-119. doi:10.1006/jtbi.2001.2406

Goodwin, G. P., Piazza, J., \& Rozin, P. (2014). Moral character predominates in person perception and evaluation. Journal of Personality and Social Psychology, 106, 148-168. doi:10.1037/a0034726

Habashi, M. M., Graziano, W. G., \& Hoover, A. H. (2016). Searching for the Prosocial Personality: A Big Five Approach to Linking Personality and Prosocial Behavior. Personality and Social Psychology Bulletin, 42, 1177-1192. doi: $10.1177 / 0146167216652859$

Hardy, C. L., \& Van Vugt, M. (2006). Nice guys finish first: the competitive altruism hypothesis. Personality and Social Psychology Bulletin, 32, 1402-1413. doi:10.1177/0146167206291006

Johnson, R. C., Danko, G. P., Darvill, T. J., Bochner, S., Bowers, J. K., Huang, Y. H., . . . Pennington, D. (1989). Cross-Cultural Assessment of Altruism and Its Correlates. Personality and Individual Differences, 10, 855-868. doi:10.1016/0191-8869(89)90021-4

Judd, C. M., Westfall, J., \& Kenny, D. A. (2017). Experiments with More Than One Random Factor: Designs, Analytic Models, and Statistical Power. Annual Review of Psychology, 68, 601-625. doi:10.1146/annurev-psych-122414-033702

Kawamura, Y., \& Kusumi, T. (2017). Selfishness is attributed to men who help young women: 


\section{COST AND BENEFIT OF ALTRUISM}

Signaling function of male altruism. Letters on Evolutionary Behavioral Science, 8, 4548. doi:10.5178/lebs.2017.64

Klein, N., \& Epley, N. (2014). The topography of generosity: asymmetric evaluations of prosocial actions. Journal of Experimental Psychology: General, 143, 2366-2379. doi:10.1037/xge0000025

Kurzban, R., Burton-Chellew, M. N., \& West, S. A. (2015). The evolution of altruism in humans. Annual Review of Psychology, 66, 575-599. doi:10.1146/annurev-psych-010814-015355

Kuznetsova, A., Brockhoff, P. B., \& Christensen, R. H. B. (2017). lmerTest Package: Tests in Linear Mixed Effects Models. Journal of Statistical Software, 82, 1-26. doi:10.18637/jss.v082.i13

Lüdecke, D. (2019). sjstats: Statistical Functions for Regression Models (Version 0.17.5). doi:10.5281/zenodo. 1284472

Lacetera, N., \& Macis, M. (2010). Social image concerns and prosocial behavior: Field evidence from a nonlinear incentive scheme. Journal of Economic Behavior \& Organization, 76, 225-237. doi:10.1016/j.jebo.2010.08.007

Lin-Healy, F., \& Small, D. A. (2012). Cheapened altruism: Discounting personally affected prosocial actors. Organizational Behavior and Human Decision Processes, 117, 269-274. doi:10.1016/j.obhdp.2011.11.006

Lin-Healy, F., \& Small, D. A. (2013). Nice Guys Finish Last and Guys in Last Are Nice: The Clash Between Doing Well and Doing Good. Social Psychological and Personality Science, 4, 692-698. doi:10.1177/1948550613476308

MacAskill, W. (2015). Doing good better : How effective altruism can help you make a difference. New York, N.Y.: Gotham Books. 


\section{COST AND BENEFIT OF ALTRUISM}

Newman, G. E., \& Cain, D. M. (2014). Tainted altruism: when doing some good is evaluated as worse than doing no good at all. Psychologial Science, 25, 648-655. doi:10.1177/0956797613504785

Oda, R., Dai, M., Niwa, Y., Ihobe, H., Kiyonari, T., Takeda, M., \& Hiraishi, K. (2013). SelfReport Altruism Scale Distinguished by the Recipient (SRAS-DR): Validity and reliability. The Japanese journal of psychology, 84, 28-36. doi:10.4992/jjpsy.84.28

West, S. A., Griffin, A. S., \& Gardner, A. (2007). Social semantics: altruism, cooperation, mutualism, strong reciprocity and group selection. Journal of Evolutionary Biology, 20, 415-432. doi:10.1111/j.1420-9101.2006.01258.x

Westfall, J. (2016). PANGEA: Power ANalysis for GEneral Anova designs. Unpublished manuscript. Retrieved from http://jakewestfall.org/publications/pangea.pdf

Willer, R. (2009). Groups reward individual sacrifice : The status solution to the collective action problem. American Sociological Review, 74, 23-43. doi:10.1177/000312240907400102

Zhang, Y., \& Epley, N. (2009). Self-centered social exchange: differential use of costs versus benefits in prosocial reciprocity. Journal of Personality and Social Psychology, 97, 796810. doi:10.1037/a0016233

Zheng, L., Wang, Q., Cheng, X., Li, L., Yang, G., Sun, L., . . Guo, X. (2016). Perceived reputation of others modulates empathic neural responses. Experimental Brain Research, 234, 125-132. doi:10.1007/s00221-015-4434-2 